\title{
Effects of Combustion Gases on Escape Performance of the Baboon and the Rat
}

\author{
HAROLD L. KAPLAN \\ Department of Fire Technology \\ Southwest Research Institute \\ P.O. Drawer 28510
}

San Antonio, Texas 78284, USA

\section{ABSTRACT}

In postcrash aircraft fires, only a few minutes are often available for egress. To assess the potential of combustion gases to impair human escape, a signalled avoidance task was developed for use with the juvenile baboon. After a 5-minute exposure, the animal was required to select and depress the correct lever to open an escape door and exit into the adjacent compartment of a shuttlebox. With $\mathrm{C} 0$, the $\mathrm{EC}_{50}$ for escape failure was $6850 \mathrm{ppm}$. Acrolein (12 to $2780 \mathrm{ppm}$ ) neither prevented escape nor affected escape times, despite irritant effects at all concentrations. Similar results were obtained with $\mathrm{HCl}$ (190 to $17,200 \mathrm{ppm}$ ) in that, all animals successfully performed the escape task, even at concentrations that produced severe post-exposure effects and lethality. With a comparable shuttlebox and escape paradigm for rats, the $\mathrm{EC}_{50}$ of $\mathrm{CO}$ was $6780 \mathrm{ppm}$. Five-minute exposures to $\mathrm{HCl}(11,800$ to $76,730 \mathrm{ppm})$ did not prevent escape but severe post-exposure respiratory effects and lethality occurred at 15,000 ppm and higher. In both species, $\mathrm{HCl}$ did not affect escape time but the number of intertrial responses was significantly related to concentration. The results indicate that the rat and the baboon have a comparable tolerance to $\mathrm{CO}$ and irritant gases and that laboratory test methods of incapacitation of rodents may be useful in evaluating the potential of combustion gas atmospheres containing $c 0$ and irritant gases to prevent human escape.

\section{INTRODUCTION}

Al1 commercial aircraft contain a wide variety of interior polymeric materials which, when combusted, evolve toxic decomposition products. The most prevalent product is carbon monoxide (CO), but other toxicants may be formed, depending on the chemical structure of the material and the combustion conditions. The fire gases are often classified into two major classes, the asphyxiants or hypoxia-producing toxicants and the irritants.

For passengers to survive a postcrash aircraft fire, their escape capability must not be severely impaired by toxic combustion gases during the few minutes available for egress. Our knowledge of the potential for these gases to impair human escape performance is very limited. In studies of the hypoxia-producing toxicants ( $\mathrm{CO}$ and hydrogen cyanide $[\mathrm{HCN}])$, laboratory test methods generally have utilized loss of gross locomotor function or of shock-avoidance response to measure the incapacitating effects of these gases (1). Although the mechanisms of action of both $\mathrm{CO}$ and $\mathrm{HCN}$ appear comparable in the rodent and man, the correlation between incapacitation of rodents and loss of escape capability in humans has not been established. As for the irritant combustion gases, studies with

This research study was supported under Federal Aviation Administration Contract No. DTFA03-81-00065. 
rodents have shown that sensory irritants cause a reflex inhibition of respiratory rate whereas a temporary increase in respiratory rate occurs upon inhalation of pulmonary irritants (2). The relevance of these respiratory effects in the rodent to human escape capability also has not been established.

These studies were conducted in order to assess the potential of asphyxiant and irritant combustion gases to impair human escape performance, using a nonhuman primate model and an operant escape task. A secondary objective was to evaluate the usefulness of presently used laboratory methods with rodents to predict the potential of these gases to prevent human escape.

\section{METHODS}

\section{Effects of Gases on Escape Performance of Nonhuman Primates}

Animal subjects. Male juvenile (ages 2 to 3 years) baboons (Superspecies Papio cynocephalus) were obtained from a breeding colony at the Southwest Foundation for Biomedical Research, San Antonio, Texas. All animals were healthy and free of respiratory problems at the beginning of the study.

Exposure and escape performance test system. The system for exposure of animals and measurement of escape performance (Figure 1) basically consisted of three elements: (1) a gas mixing chamber and associated ducts and valves; (2) a gas bypass 10op; and (3) a primate escape performance test apparatus. Exposure atmospheres were premixed in the gas mixing chamber and recirculated through the gas bypass loop until the desired concentrations were obtained. For exposure of an animal, activation of appropriate valves removed the gas bypass loop from the system and the atmosphere was recirculated between the gas mixing chamber and one chamber of the primate escape performance test apparatus.

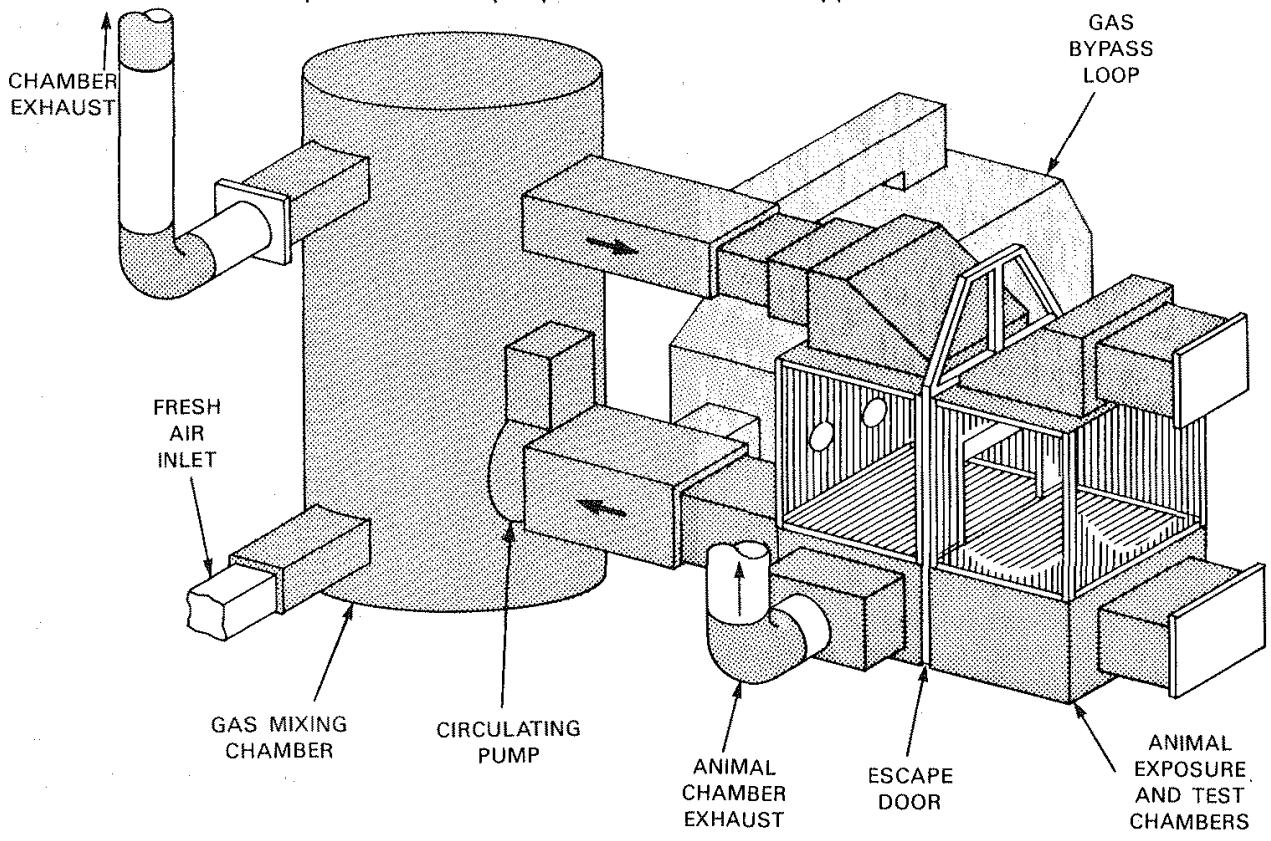

FIGURE 1. Gas mixing/exposure system and escape performance test apparatus for primate tests 
The primate escape performance test apparatus was a shuttlebox consisting of two identical chambers separated by a vertically sliding escape door. Within each chamber was a cage constructed of aluminum bars to which constant current shockers could provide 4 to 8 milliamps of current. Two response levers were mounted on the wall opposite the escape door in each chamber and, above each lever, were two cue lights, one white and one red. During a trial, the white light was activated over one lever and the red light was activated over the other lever, with the sequence randomized by a computer control system. Depression of the lever over which the white light was "on" caused the escape door to open; depression of the lever when its red light was "on" had no effect.

Escape performance paradigm. The behavioral paradigm for measurement of escape performance was a signalled avoidance task. An audio cue (Sonalert buzzer) signalled the start of a trial and, simultaneously, the white light over one lever and the red light over the other lever were turned on to indicate to the subject which lever was the correct response, i.e., would open the escape door. Ten seconds later, an electric shock was applied to the bars of the cage and maintained for 20 seconds. If the subject pressed the correct lever and moved through the door opening into the adjacent chamber within 10 seconds, the response was designated an "avoidance." If the animal pressed the correct lever and exited after 10 seconds, but within 30 seconds, the response was termed an "escape." The response was a "failure" if the subject did not exit the exposure chamber or exited after 30 seconds. Both avoidance and escape responses were considered escapes or successful performance in the treatment of the data.

A behavioral control system, consisting of a Data General Nova 3 minicomputer equipped with a BRS/LVE Corporation INTERACT System, was used to program and control the escape performance equipment and paradigm and to record performance data. Performance data included: (1) time to first lever press; (2) time to first correct lever press; (3) time to chamber exit; (4) number of correct and incorrect lever presses; (5) number of intertrial lever presses (ITIs), i.e., number of presses made prior to initiation of a trial; (6) cumulative number of avoidances and escapes; and (7) number of shock pulses delivered.

Exposures. The effects on escape performance of a five-minute exposure to each of three combustion gases, $\mathrm{CO}$, acrolein and hydrogen chloride (HCl), were investigated. In each experiment, the exposure of a subject was initiated after the desired concentration of the gas was equilibrated in the gas mixing chamber, thereby enabling the atmosphere to rapidly reach a stable concentration in the exposure chamber. With $\mathrm{CO}$, each of six subjects was exposed to each of four concentrations in order to evaluate concentration-response relationships for the escape performance measures and to derive an $E_{50}$ value for escape failure. With acrolein and $\mathrm{HCl}$, usually concentrations were increased in successive experiments until post-exposure lethalities occurred, in an effort to determine a threshold concentration for escape failure. Some animals exposed to lower concentrations were exposed to these gases a second time, with weeks to months intervening and provided the subjects were asymptomatic.

Generation and analysis of exposure atmospheres. Compressed gas cylinders of pure $\mathrm{CO}$ were used to generate $\mathrm{CO}$ atmospheres, by metering the gas through a calibrated flowmeter into the gas recirculation system. Continuous analysis of these atmospheres was accomplished by means of a Beckman 865 non-dispersive infrared analyzer. For the experiments with acrolein, predetermined quantities of liquid acrolein were injected directly into the recirculation system to obtain the desired concentrations of exposure atmospheres. Continuous analysis of these atmospheres was accomplished by means of a hydrocarbon analyzer calibrated by gas chromatographic analyses of frequent syringe samples withdrawn from sampling ports in the exposure chamber. Hydrogen chloride atmospheres were generated by the same procedure as for $\mathrm{CO}$, using a compressed gas cylinder of pure 
HC1. During each exposure, five one-minute samples of the atmosphere were obtained using soda-lime aborption tubes; these samples were desorbed with water and analyzed by titration with mercuric nitrate (3).

\section{EFFECTS OF GASES ON ESCAPE PERFORMANCE OF THE RAT}

Animal subjects. Male Sprague-Dawley rats (Timco Breeding Laboratories, Houston, Texas), weighing between 340 and 500 grams, were used in these studies.

Escape performance test apparatus and paradigm. A modified commercially avai Table shuttlebox (Lafayette Instrument Company, Model No. 85103), consisting of two identical chambers separated by a vertically sliding partition driven by an electric motor, was used to measure escape performance. Two levers were mounted on each side of the partition in each chamber and a white cue light was mounted above each lever. The floor and top of each chamber consisted of a grid of electrically isolated bars for the administration of an electric shock to the subjects. The escape performance paradigm and behavioral control system were the same as for the primates except that the rat was not required to discriminate between red and white cue lights because of the lengthy training time required. Each trial was initiated with a tone (Sonalert buzzer) and the lighting of the white light over each of the two levers. Pressing of either lever by the rat opened the partition and allowed the animal to escape into the adjacent chamber. Responses were designated "avoidance," "escape" or "failure" according to the same criteria as in the primate studies.

Exposures. The effects on escape performance of five-minute exposures to c0 and $\mathrm{HCT}$ were investigated in the rat. With $\mathrm{CO}$, each of four or six animals was exposed to each of four concentrations in order to evaluate concentrationresponse relationships for the escape performance measures and to derive an $E_{50}$ value for escape failure. For these exposures, the rodent shuttlebox was placed inside the exposure chamber of the primate test system and connected to the computer control system. For the $\mathrm{HCl}$ exposures, the rodent shuttlebox was interfaced with a 300-liter acrylic exposure chamber in a manner that allowed the exposure cage to be located within the acryitic chamber and the escape cage outside of this chamber. Each animal was exposed only once to $\mathrm{HCl}$. The procedures for the generation and analyses of $\mathrm{CO}$ and $\mathrm{HCl}$ exposure atmospheres were basically the same as for the primate studies.

\section{RESULTS}

Effects of carbon monoxide on escape performance of the baboon and the rat. The results of the experiments with $\mathrm{CO}$ in Table 1 (baboons) and in Table 2 (rats) show a decreasing percentage of escaping animals, both baboons and rats, with increasing average concentrations of $\mathrm{CO}$. Linear regression analysis of performance data for the baboon did not show a statistically significant relationship between $C O$ concentration and escape time or other performance parameters of those subjects that successfully performed the escape task. In rats, however, escape time increased as co concentration increased $(p<0.05)$. None of the other performance parameters of rats was affected by exposure to $\mathrm{co}$. The concentration-response curves for escape performance of the two species (Figure 2) were obtained by plotting percentage of failures against the logarithm of the mean $\mathrm{CO}$ concentration and deriving the best fitting line by the probit method of Finney (4). From these curves, $E_{50}$ values for escape failure were determined to be $6850 \mathrm{ppm}$ (95-percent confidence limits: 6043-7773) for the juvenile baboon and $6780 \mathrm{ppm}$ (95 percent confidence limits: 6367-7271) for the rat. 
TABLE 1. Effects of Carbon Monoxide on Escape Performance of the Baboon

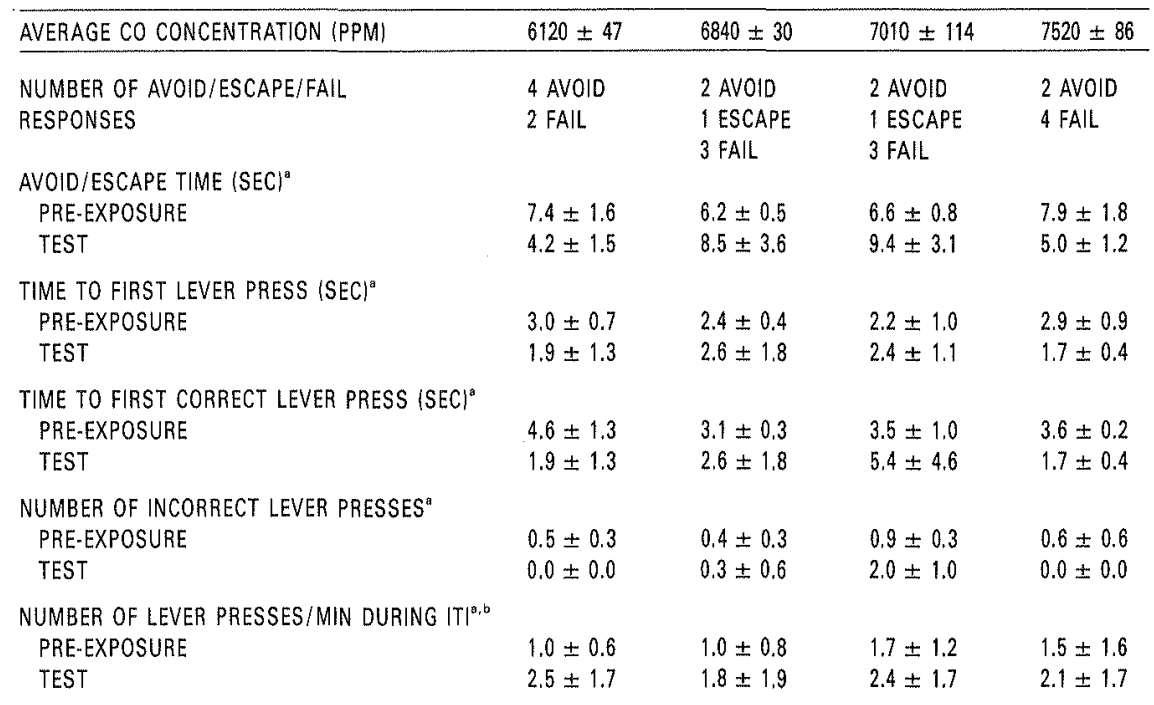

"VALUES REPRESENT MEAN $\pm S . D .(N=$ NO. OF AVOID/ESCAPE ANIMALS $)$

${ }^{\mathrm{D}} \mathrm{TTI}=$ = INTERTRIAL INTERVAL.

TABLE 2. Effects of Carbon Monoxide on Escape Performance of the Rat

\begin{tabular}{|c|c|c|c|c|}
\hline AVERAGE CO CONCENTRATION (PPM) & $6150 \pm 48$ & $6730 \pm 46$ & $6990 \pm 47$ & $7220 \pm 195$ \\
\hline $\begin{array}{l}\text { NUMBER OF AVOID/ESCAPE/FALL } \\
\text { RESPONSES }\end{array}$ & $\begin{array}{l}3 \text { ESCAPE } \\
\text { I FAlL }\end{array}$ & $\begin{array}{l}4 \text { ESCAPE } \\
2 \text { FAlL }\end{array}$ & $\begin{array}{l}1 \text { AVOID } \\
1 \text { ESCAPE } \\
4 \text { FAlL }\end{array}$ & $\begin{array}{l}1 \text { ESCAPE } \\
3 \text { FAlL }\end{array}$ \\
\hline $\begin{array}{l}\text { AVOID/ESCAPE TIME }\langle\text { SEC }\rangle^{2} \\
\text { PRE-EXPOSURE } \\
\text { TEST }^{b}\end{array}$ & $\begin{array}{r}6.4 \pm 4.3 \\
12.2 \pm 1.2\end{array}$ & $\begin{array}{r}6.3 \pm 1.8 \\
18.6 \pm 5.5\end{array}$ & $\begin{array}{l}3.3 \pm 1.6 \\
8.7 \pm 1.6\end{array}$ & $\begin{array}{c}11.3 \pm 5.4 \\
18.9\end{array}$ \\
\hline $\begin{array}{l}\text { TIME TO FIRST LEVER PRESS }(S E C)^{\circ} \\
\text { PRE-EXPOSURE } \\
\text { TEST }\end{array}$ & c & $\begin{array}{r}4.8 \pm 1.9 \\
14.4 \pm 3.5\end{array}$ & $\begin{array}{l}2.2 \pm 1.5 \\
6.3 \pm 5.4\end{array}$ & $\mathrm{G}$ \\
\hline $\begin{array}{l}\text { NUMBER OF LEVER PRESSES } \\
\text { PRE-EXPOSURE } \\
\text { TEST }\end{array}$ & $\begin{array}{l}1.2 \pm 0.1 \\
2.0 \pm 1.1\end{array}$ & $\begin{array}{l}1.0 \pm 0.1 \\
1.0 \pm 0.0\end{array}$ & $\begin{array}{l}1.0 \pm 0.0 \\
1.5 \pm 0.7\end{array}$ & $\begin{array}{c}1.2 \pm 0.4 \\
1.0\end{array}$ \\
\hline $\begin{array}{l}\text { NUMBER OF LEVER PRESSES/MIN DURING ITI }{ }^{a, t} \\
\text { PRE-EXPOSURE } \\
\text { TEST }\end{array}$ & $\begin{array}{l}0.2 \pm 0.3 \\
0.6 \pm 0.6\end{array}$ & $\begin{array}{l}0.1 \pm 0.1 \\
1.2 \pm 1.1\end{array}$ & $\begin{array}{l}0.3 \pm 0.6 \\
0.9 \pm 0.6\end{array}$ & $\begin{array}{l}0.1 \pm 0.1 \\
1 . \hat{0} \pm 1.0\end{array}$ \\
\hline
\end{tabular}

VVALUES EXPRESSED AS MEAN $\pm S . D,(N=$ NO. OF AVOID/ESCAPE ANIMALS $)$.

'TEST VALUES SIGHIFICANTLY $(p<0,05$ ) RELATED TO CO CONCENTRATION.

'DATA NOT AVAILABLE DUE TO EQUIPMENT MALFUNCTION.

${ }^{\circledR} I T I=$ INTERTRIAL INTERVAL. 


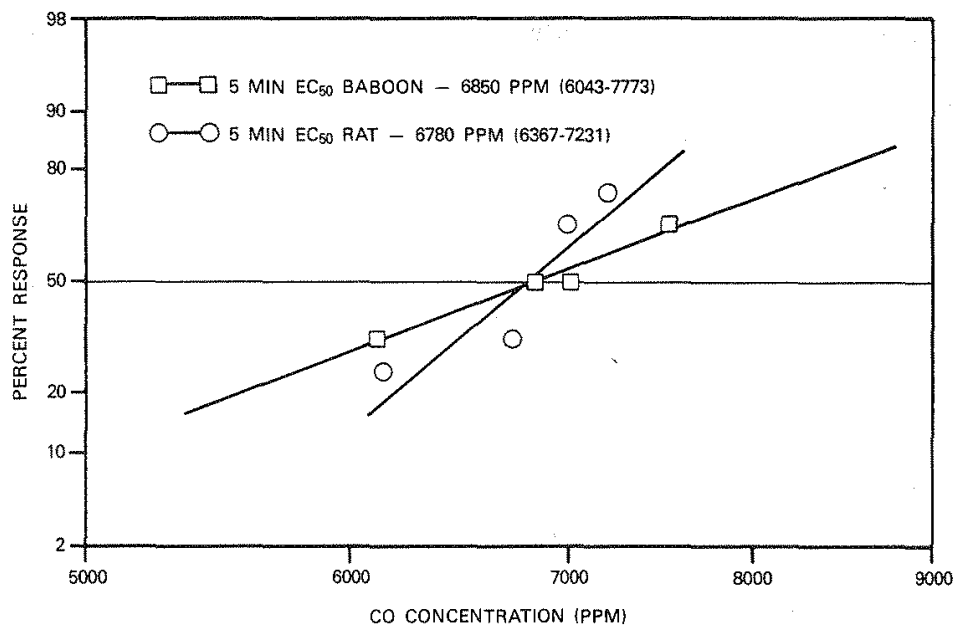

FIGURE 2. Concentration-response curves and $E C_{50}$ values for escape failure of the baboon and the rat by carbon monoxide

Effects of acrolein on escape performance of the baboon. In nine experiments in which baboons were exposed for five minutes to acrolein at average concentrations of 12 to $2780 \mathrm{ppm}$ (Table 3), all subjects except one made avoidance responses. In the one exception $(95 \mathrm{ppm})$, the subject was mobile and did not exhibit signs of incapacitation but did not perform the escape task. The result is not considered meaningful, however, because the shock stimulus did not operate in this experiment and, in addition, animals exposed to much higher concentrations were able to perform the task. In most experiments, test escape times were less than pre-exposure mean escape times, suggesting that the animals were attempting to escape from the irritant environment, but the difference was not statistically significant. Nor did statistical analyses of the data indicate any effect of acrolein on other performance parameters. Although escape performance was not impaired, irritant effects were evident at all concentrations of acrolein, increasing in severity from blinking and closure of the eyes and rubbing of the eyes/nose at lower concentrations to salivation, nasal discharge, violent shaking of the head and nausea at higher concentrations. The animals exposed to the two highest concentrations (1025 and $2780 \mathrm{ppm}$ ) expired at 24 and 1.5 hours, respectively, following exposure, with severe pulmonary edema and hemorrhage as the most significant histopathologic findings.

Effects of hydrogen chloride on escape performance of the baboon and the rat. In eight experiments in which baboons were exposed for five minutes to average $\mathrm{HCl}$ concentrations of 190 to $17,290 \mathrm{ppm}$ (Table 4), all animals performed the escape task, with avoidance responses by six subjects and escape responses by two subjects. Statistical analyses of the data did not indicate a significant relationship between acrolein concentration and escape time or other performance parameters except for intertrial responses, which showed a significant increase with increasing concentrations $(p<0.05)$. Irritant effects were observed at all concentrations except the lowest, increasing in severity from coughing and frothing at the mouth at lower concentrations to profuse saliva- 
TABLE 3. Effects of acrolein on escape performance of the baboon

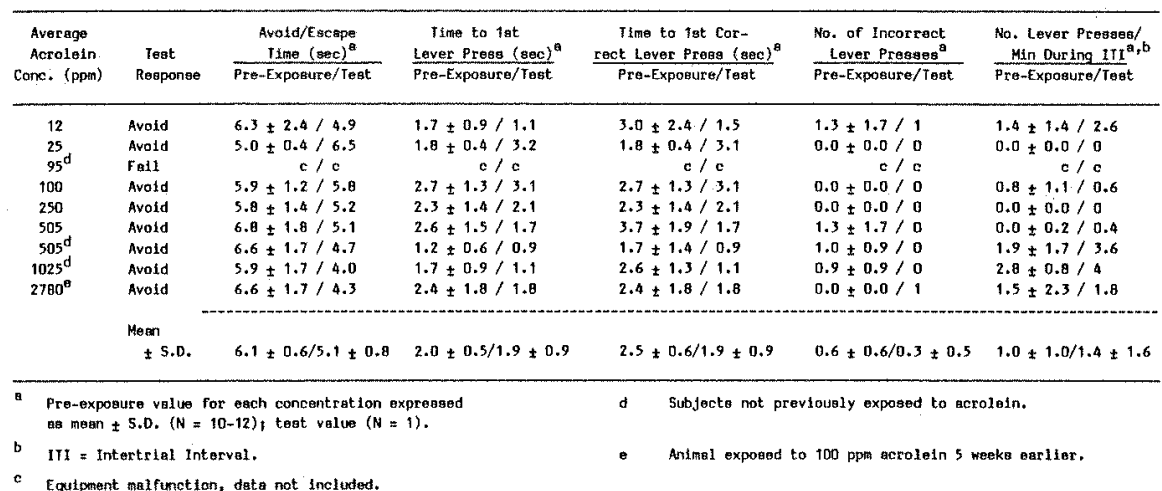

TABLE 4. Effects of hydrogen chloride on escape performance of the baboon

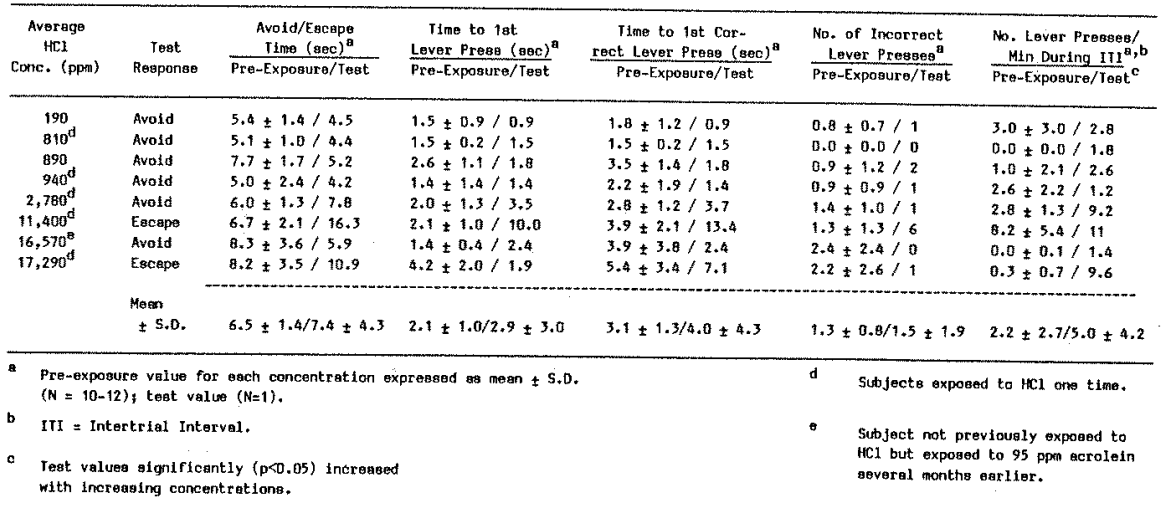


tion, blinking/rubbing of eyes, and shaking of head at higher concentrations. In animals exposed to the two highest concentrations $(16,570$ and $17,290 \mathrm{ppm})$, severe dyspnea persisted after exposure, with death at 18 and 76 days, respectively, post exposure. Histopathologic examination revealed pneumonia, pulmonary edema and tracheitis with epithelial erosion.

In twelve experiments in which rats were exposed for 5 minutes to $H C l$ at concentrations of 11,800 to $87,660 \mathrm{ppm}$ (Table 5), all animals performed the escape task, except at the highest concentration which resulted in death during exposure. Statistical analyses of the data did not indicate any effect of $\mathrm{HCl}$ on escape time or other performance parameters, except for the number of intertrial responses which significantly $(p<0.05)$ increased with increasing concentration. All concentrations produced signs of severe irritation (respiratory tract and/or eyes), with persistent respiratory effects and post-exposure lethality produced by exposure to concentrations of $15,250 \mathrm{ppm}$ and greater. The times at which post-exposure deaths occurred ranged from 3 minutes to 13 days following exposure, and were correlated inversely with $\mathrm{HCl}$ concentration.

TABLE 5. Effects of hydrogen chloride on escape performance of the rat

\begin{tabular}{|c|c|c|c|c|c|}
\hline $\begin{array}{l}\text { Average } \\
\text { HCl } \\
\text { Cone. (ppm) }\end{array}$ & $\begin{array}{l}\text { Test } \\
\text { Response }\end{array}$ & $\frac{\text { Escape Time (gec) }}{\text { Pre-Exposure/Test }}$ & $\begin{array}{l}\text { Time to First } \\
\text { Lever Presa (ses) } \\
\text { Pre-Exposure/Test }\end{array}$ & $\begin{array}{c}\begin{array}{c}\text { Nuxber of } \\
\text { Lever Presses }\end{array} \\
\text { Pre-Exposure/lest }\end{array}$ & $\begin{array}{l}\text { No. Lever Preses/ } \\
\frac{\text { Min During } 1 T I^{\mathrm{R}, \mathrm{b}}}{\text { Pre-Exposure/Test }}\end{array}$ \\
\hline 11,800 & Eseяpe & $15.5 \pm 5.1 / 25.7$ & $11.6 \pm 1.3 / 14.4$ & $1.1 \pm 0.4 / 1$ & $0.0 \neq 0.0 / 0.6$ \\
\hline 14,410 & Eacape & $13.3 \pm 1.2 / 13.9$ & $11.3 * 1.6 / 13.1$ & $1.2 \pm 0.4 / 2$ & $0.8+1.0 / 2.8$ \\
\hline 15,250 & Escepe & $13.5 \div 1.7 / 15.3$ & $10.8 \pm 1.2 / 90.0$ & $1.4 \pm 0.5 / 6$ & $0.0 \pm 0.0 / 5.2$ \\
\hline 18,430 & Avold & $10.0 \pm 3.7 / 7.0$ & $9.5 \geq 3.8 / 6.3$ & $1.0 \pm 0.0 / 1$ & $0.5 \div 1.0 / 4.6$ \\
\hline 22,260 & Eacape & $13.5 \pm 5.3 / 21.5$ & $13.7 \pm 5.5 / 13.0$ & $1.1 \pm 0.3 / 2$ & $0.0 \pm 0.0 / 2.4$ \\
\hline 25,300 & Escape & $13.6 \pm 4.5 / 16.1$ & $13.1 \pm 4.5 / 7.9$ & $1.0 \pm 0.0 / 1$ & $0.2 \pm 0.6 / 3.2$ \\
\hline 25,950 & Escape & $15.1 \pm 5.0 / 14.0$ & $4.5 \pm 5.2 / 13.4$ & $1.5 \pm 0.9 / 1$ & $0.1 \pm 0.3 / 0.2$ \\
\hline 27,690 & Escape & $16.8 \pm 4.6 / 16.6$ & $12.5 \pm 3.8 / 10.2$ & $1.5 \pm 0.8 / 13$ & $0.3 \pm 0.8 / 3.4$ \\
\hline 50,910 & Eacape & $12.2 \pm 2.5 / 14.7$ & $10.9 \pm 1.1 / 14.0$ & $1.5 \pm 0.7 / 1$ & $0.1 \pm 0.3 / 7.0$ \\
\hline 53,900 & Avold & $13.3 \pm 2.3 / 2.9$ & $12.7 \pm 2.2 / 2.4$ & $1.1 \pm 0.3 / 1$ & $0.0 \pm 0.0 / 2.8$ \\
\hline 76,730 & Escape & $12.1 \pm 3.9 / 21.8$ & $10.6 \div 2.9 / 10.2$ & $1.0 \pm 0.0 / 11$ & $0.2 \div 0.4 / 5.8$ \\
\hline \multirow[t]{3}{*}{87,660} & Died & 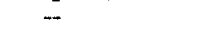 & - & -. & - \\
\hline & Nean & & & & \\
\hline & \pm S.D. & $13.5 \pm 1.8 / 15.4 \pm 6.4$ & $11.0 \pm 2.5 / 10.5 \pm 3.7$ & $1.2 \pm 0.2 / 3.6 \pm 4.4$ & $0.2 \pm 0.2 / 4.2 \pm 3.3$ \\
\hline
\end{tabular}

a Pre-exposure value expreased as mean \pm S.D. $(N=10-12)$; teat value $(N=1)$.

b Irr = Intertrial Interval

c Test values aignifieantly $\left(p^{<0.05)}\right.$ increased with increaging concentration.

\section{DISCUSSION}

The similarity of 5 -minute $E_{50}$ values for $\mathrm{CO}$-induced escape failure in the baboon and rat suggests that the rat may be a useful model for evaluating the potential of $C 0$ atmospheres to cause loss of escape capability in nonhuman primates and, possibly, in man. Additional insight into the utility of the rat as a model for man may be obtained from Kimmerle's (5) human toxicity data which indicate that symptoms produced in some individuals at between 30 and 40 percent carboxyhemoglobin ( $\mathrm{COHb}$ ) may be sufficiently severe as to prevent escape. Using the Stewart-Peterson equation (6) with a respiratory minute volume (RMV) of 20 liters (light activity), this range of $\mathrm{COHb}$ saturation may be anticipated in man after a 5-minute exposure to from 7,000 to 9,000 ppm C0. These exposures equate to a concentration-time product (Ct), i.e., accumulated dose, of 35,000 to 45,000 ppm-minutes. The 5 -minute $E C_{50} \mathrm{Ct}$ values obtained for the baboon $(34,250$ $\mathrm{ppm}-\mathrm{min})$ and the rat $(33,900 \mathrm{ppm}-\mathrm{min})$ are near this range, providing support for 
the usefulness of the the rat and baboon (with the shuttlebox) for estimating the potential of $\mathrm{C} 0$ atmospheres to prevent human escape. Comparable $\mathrm{Ct}$ values reported for incapacitation of rats by $C 0$ using other methods, such as the rotarod (7), the motor-driven exercise wheel (8) and leg-flexion shock avoidance (9), indicate that these methods, also, may have utility in estimating the effects of co-containing atmospheres on human escape capability.

In the experiments with acrolein, a five-minute exposure did not prevent the baboon from performing the escape task, even at concentrations (1025 and $2780 \mathrm{ppm}$ ) that cause post-exposure lethality. These results do not appear to be consistent with claims that the $\mathrm{RD}_{50}$ concentration of an irritant gas will incapacitate man within a few minutes $(10,11)$, in view of the reported $R D_{50}$ concentration of only $1.7 \mathrm{ppm}$ of acrolein in mice (12). The effects of acrolein on escape performance of the rat were not investigated in these studies nor are experimental data for acrolein using other methods for measuring incapacitation of rodents available in the literature. Unpublished data provided by the FAA/CAMI laboratory, however, indicate that 5-minute exposures to approximately 5000 to $10,000 \mathrm{ppm}$ of acrolein incapacitate the rat in the motor-driven exercise wheel and cause post-exposure lethality (13). It is possible that these concentrations would produce sufficient pulmonary damage in the baboon within 5 minutes to prevent performance of the escape task. Thus, both the rat and the baboon appear to be highly tolerant of the incapacitating effects of acrolein.

The results obtained with $\mathrm{HCl}$ in baboons were similar to those with acrolein in that 5-minute exposures to $\mathrm{HCl}$ did not prevent the baboon from performing the escape task, even at concentrations (approximately 17,000 ppm) that caused severe post-exposure respiratory effects and lethality. These results also do not appear to be consistent with the prediction that man will be incapacitated within a few minutes by the $\mathrm{RD}_{50}$ concentration (309 ppm in mice [12]) of $\mathrm{HCl}$. Rats, also, tolerated high concentrations of $\mathrm{HCl}(11,800$ to $76,730 \mathrm{ppm})$ without loss of performance of the escape task, although post-exposure lethaitities occurred at concentrations above approximately $15,000 \mathrm{ppm}$. These results are in accord with those of experiments conducted by the FAA/CAMI laboratory (13) in which approximately 5 to 7 minutes of exposure to 65,000 to $100,000 \mathrm{ppm}$ incapacitated rats in the motor-driven exercise wheel, with subsequent lethality.

From the results of these studies and those of Crane (13), the rat and baboon appear to be capable of enduring high concentrations of acrolein or $\mathrm{HC} 1$ without incapacitation or loss of escape capability. These results are not consistent with the conclusions of Henderson and Haggard (14) that a concentration of $24 \mathrm{ppm}$ of acrolein is unbearable and of $10 \mathrm{ppm}$ and above is lethal to man in a short time and that inhalation of $1000 \mathrm{ppm}$ of $\mathrm{HCl}$ is dangerous. It is possible that this inconsistency is due to species differences in sensitivity to irritant gases. However, it is also possible that man can tolerate higher concentrations of irritant gases than anticipated, when unavoidable, without complete loss of escape capability.

\section{ACKNOWLEDGEMENTS}

The author wishes to acknowledge the significant contributions to this study by the co-investigators of the Department of Fire Technology and the Department of Bioengineering of the Southwest Research Institute, the invaluable data and technical recommendations provided by Dr. Charles R. Crane of the FAA/CAMI Laboratory and the guidance and advice given by Mr. Constantine P. Sarkos of the Federal Aviation Administration. 


\section{REFERENCES}

1. Kaplan, H. L., Grand, A. F. and Hartzell, G. E., Combustion Toxicology: Principles and Test Methods, Technomic Publishing Company, Incorporated, Lancaster, Pennsylvania (1983).

2. Alarie, Y., "Sensory Irritation by Airborne Chemicals," CRC Critical Reviews in Toxicology, Volume 2, pp. 299-362 (1972).

3. Grand, A. F., Kaplan, H. L., Beitel, J. J., III, Switzer, W. G., and Hartzell, G. E., "An Evaluation of Toxic Hazards from Full-Scale Furnished Room Fire Studies," Fire Safety: Science and Engineering, ASTM STP 882, T. Z. Harmathy, Ed., American Society for Testing and Materials, Philadelphia, in press (1985).

4. Finney, D. J., "Probit Analysis" (3rd ed.), Cambridge University Press (1971).

5. Kimmerle, G., "Aspects and Methodology for the Evaluation of Toxicological Parameters During Fire Exposure," The Journal of Fire and Flammability Combustion Toxicology Supplement, Vol. 1 (February 1974).

6. Stewart, R. D., Peterson, J. E., Fisher, T. N., Hosko, M. J., Baretta, E. D., Dodd, H. C., and Herrmann, A. A., "Experimental Human Exposure to High Concentrations of Carbon Monoxide," Archives of Environmental Health, Volume 26, pp. 1-7 (January 1973).

7. Southwest Research Institute, Unpubiished Work.

8. Crane, C. R., et al., "Inhalation Toxicology: I. Design of a Small-Animal Test System; II. Determination of the Relative Toxic Hazards of 75 Aircraft Cabin Materials," Report No. FAA-AM-77-9 Prepared for Office of Aviation Medicine, Federal Aviation Administration (March 1977).

9. Packham, S. C., and Hartzel1, G. E., "Fundamentals of Combustion Toxicology in Fire Hazard Assessment," $\mathrm{J}$. of Testing and Evaluation, Volume 9, No. 6, p. 341 (1981).

10. Barrow, C. S., Lucia, H., Stock, M. F. and Alarie, Y., "Development of Methodologies to Assess the Relative Hazards from Thermal Decomposition Products of Polymeric Materials," Amer. Ind. Hyg. Assoc. J., Vol. 40, pp. 408-423 (May 1979).

11. Kane, L. E., Barrow, C. S. and Alarie, Y., "A Short-Term Test to Predict Acceptable Levels of Exposure to Airborne Sensory Irritants," Amer. Ind. Hyg. Assoc. J., Vol. 40, pp. 207-229 (1979).

12. Alarie, Y., "Toxicological Evaluation of Airborne Chemical Irritants and Allergens Using Respiratory Reflex Reactions," Proceedings of the Inhalation Toxicology and Technology Symposium, sponsored by The Upjohn Company, Ka7amazoo, Michigan (0ctober 23-24, 1980).

13. Crane, C. R., Unpublished Data.

14. Henderson, Y. and Haggard, H. W. Noxious Gases, 2nd Edition, New York, Reinhold (1943). 